answer, e.g. Tell me about an important paper you have read recently.

You must know your $\mathrm{CV}$ in detail and be able to back up everything it says about you. Never apologise for yourself or your failings. When asked at the end if you have any questions, say No. You should have prepared for the post carefully enough not to need to ask anything. Remember that the friendly consultant you met in her office may be very harsh when questioning you in front of her colleagues.

Don't be pathologically honest. We know that you will settle for any good job that's going, but you have to convince the panel that you really want to work for them.

Always ask for feedback after the interview. Force yourself to do this even if you don't feel like it. This is vital information. (Some places will offer feedback).

However, keep a sense of proportion. That interview is over. The next interview may well require a different balance of qualities. I well remember attending two interviews in two days (a mistake in itself). I felt my performance was much the same at both. However, at the first I was told that I came across too strongly-I think they feared I might be dangerously self-opinionated. At the second I was criticised for under-selling myself.

Take stock. After a number of failures, stop and review your plan of campaign. You will be beginning to feel dependent and worn down if not frankly depressed, so get someone else to help you. Check through everything again. This should include asking to read your references or at least discussing them.

Don't take it personally when you are rejected-especially if an insider or late applicant is selected. By all means analyse your performance. But this is not like the exam. The odds against you are much higher.

A good friend of mine, now an ENT senior registrar, told me how a colleague of his had applied rather hopefully for an SR post in the Midlands. Two rival hospitals there had each put up a strong internal candidate. Neither wanted the other to succeed. They agreed on the third choice, my friend's colleague was duly appointed. Take heart. Stranger things have happened.

\section{REFERENCES}

${ }^{1}$ Healy, K. (1985) Job hunting in London, 1984. Bulletin of the Royal College of Psychiatrists, 9, 10-11.

${ }^{2}$ How to Do It-2nd edition (1985). Articles from the British Medical Journal. London: British Medical Association.

${ }^{3}$ TUPNELL, G. (1984) How to get the senior registrar post you want. Bulletin of the Royal College of Psychiatrists, 8, $214-216$.

${ }^{4}$ RHODEs, P. (1983) Letters to a young doctor (Applying for jobs. Interviews: sell yourself. Interviews: what happens). British Medical Journal, 286, 618-620; 706-707; 784-785.

\title{
Merck Sharp \& Dohme Prizes for Young Psychopharmacologists
}

Two prizes of $£ 250$ each are to be awarded in 1987 by the British Association for Psychopharmacology, with funds provided by Merck Sharp \& Dohme Ltd, for outstanding research in basic psychopharmacology and clinical psychopharmacology respectively. Applications are invited from research workers under the age of 35 active in one or other of these fields. Applications should be submitted to Professor M. H. Lader at the Institute of Psychiatry, De Crespigny Park, Denmark Hill, London SE5 8AF, and should comprise:

1. A detailed CV;
2. Three key published papers which have undergone peer review;

3. A 250 -word resume of the applicant's achievements to date and plans for the future.

A condition of the award of the prize is that the successful applicant will write a review paper setting the results of his research against the literature of the topic, for publication in the new journal of the Society, to be called Journal of Psychopharmacology.

Applications should be received before the 30 September 1987.

\section{International Research Prize}

The Board of Management of the Averroes Foundation, in collaboration with the Andalusian Institute of Mental Health (IASAM) has decided to create a prize, to be awarded annually, to encourage the development of research in the mental health care of children and young people. It will be called the Arturo Sanmartin Prize in memory of the distinguished Spanish psychiatrist. Completed application forms and details of the research project must be received by the Foundation before 10 September 1987. Further information: Fundacion Averroes, Avda. Del Sur 13, 18071 Granada, Spain. 